\title{
البحوث المسرحية
}

\section{المسرح البابلي، تأريخه وطرازه وخصائصه "دراسة تاريخية مقارية"}

Babylonian theater (Its history, models and properties) a historical comparative study

\section{محمد صبري صالخ}

\section{Mohammed sabri saleh}

\section{الملاصة}

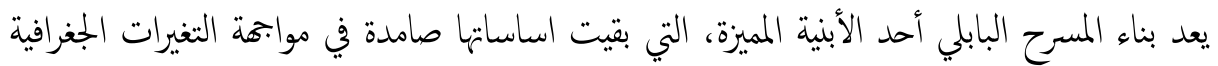

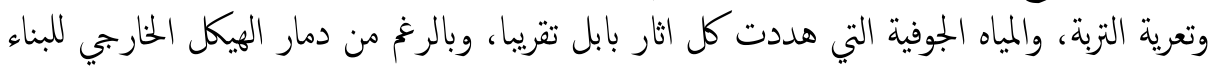

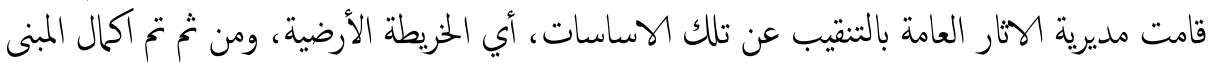

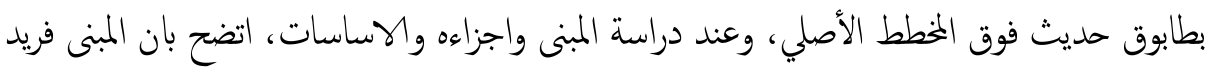

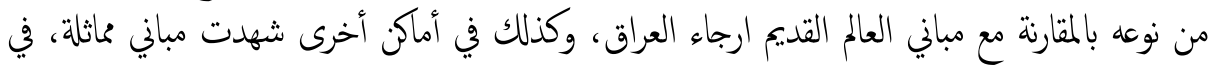

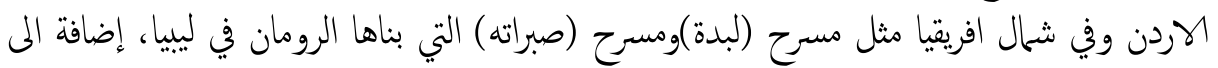

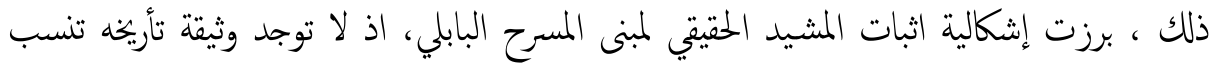

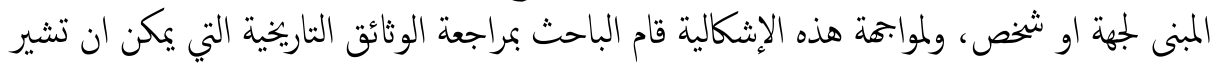

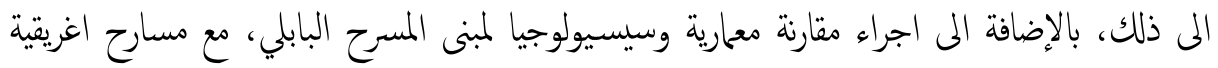

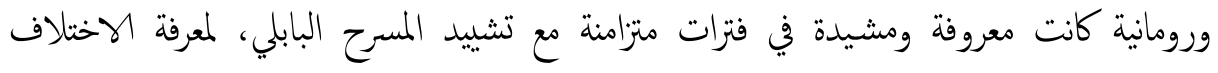
والتشابه بنيها.

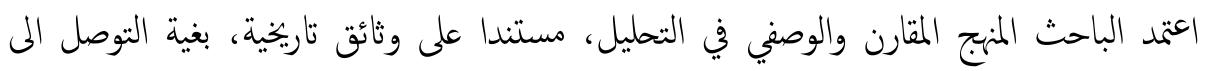

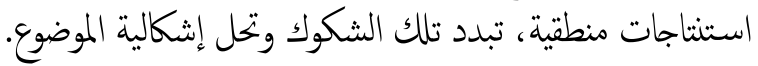

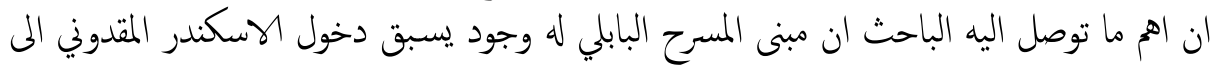

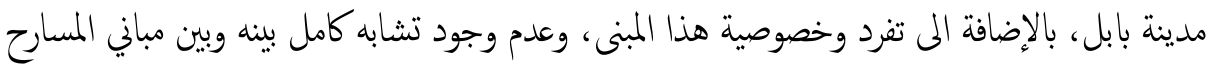
الاغريقية والرومانية.

\section{Abstract}

The building of the Babylonian theater is considered as one of the distinctive buildings where its foundations have remained steadfast in the face of geographical changes, social's erosion and groundwater that threatened almost all traces of Babylon despite the destruction of the outer structure of the building. The general directorate of antiques performed 
prospection for those foundations (the ground map), and then the building was completed by new bricks over the original scheme. It became clear when examining the building; its components and foundations, that the building is unique in comparison with the old buildings of the world throughout Iraq. There are similar buildings in other places like Jordan and North Africa such as Leptis Magna's theater and Sabratha's theater which were built by the Greeks in Libya. A confusion has been emerged about the real builder of the theater where there is no document dated whether the building attributed to a company or a person. To manage this problem, the researcher reviewed the historical documents that could refer to that case. Moreover, he conducted an architectural and sociological comparison between Babylonian theater and the Greek and Roman theaters which were known and built in synchronized intervals with the creation of the Babylonian theater in order to know the differences and similarities between them.

The researcher used descriptive and comparative method in the analysis, based on historical documents in order to reach logical conclusions that may dispel those doubts and solve the problem.

The most important findings were the existence of the Babylonian theater building before entering Alexander the Great to the city of Babylon, the uniqueness and specificity of this building and the lack of full similarity between Babylonian theater and the Greek and Roman theaters.

\section{مشكلة البحث والحاجة إليه:}

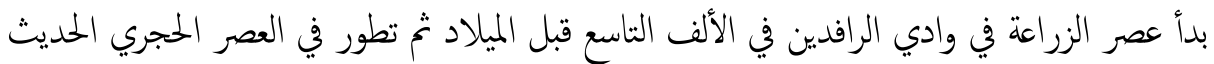

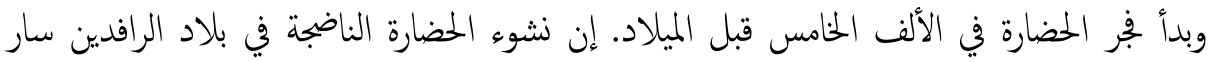
بخطوات ثابتة وبأطوار متعاقبة. شهد العراق خلال هذه الأطوار اتساع الزراعة وبداية الحياة الحضرية ونشوء أول مدنية في تاريخ

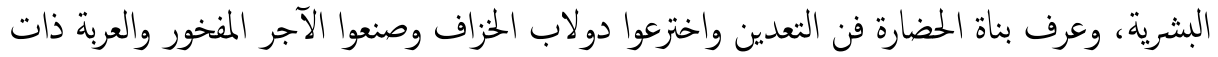




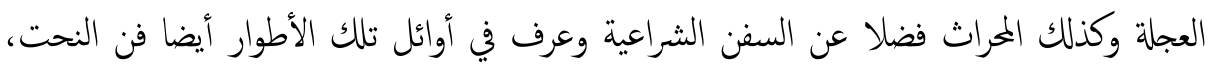

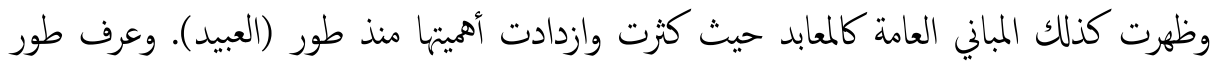

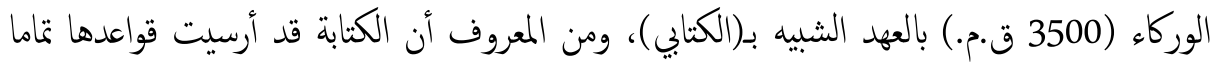

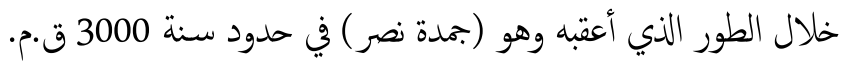

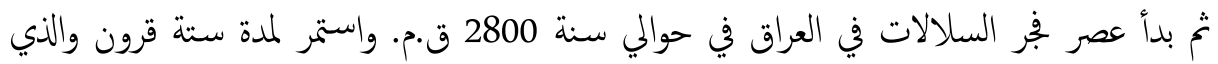

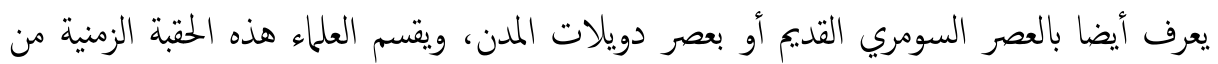
تاريخ العراق إلى ثلاثة عصور هي على التوالي:

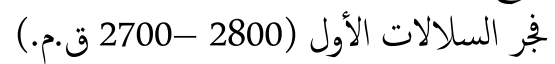

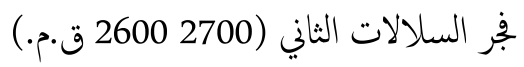

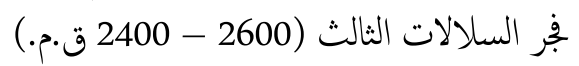

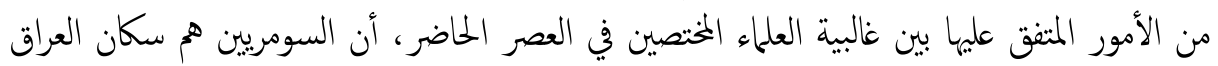

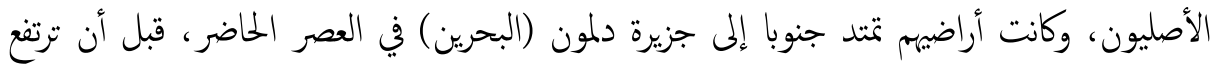

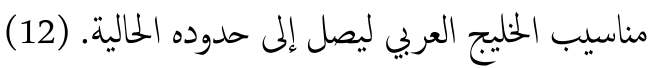

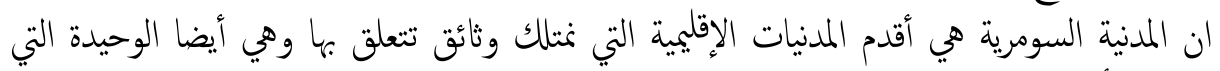

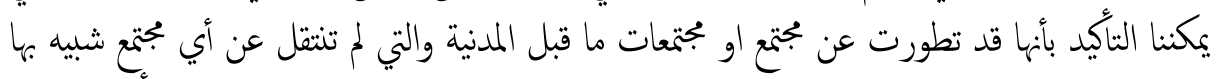

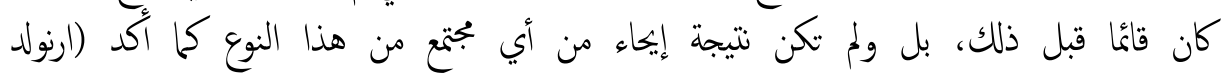

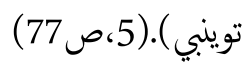
في فجر السلالات الأولى ازدهر فن العهارة، وتجسد في بناء القصور والمعابد والمباني الضخمة، كما تطور

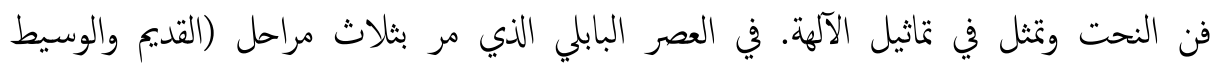

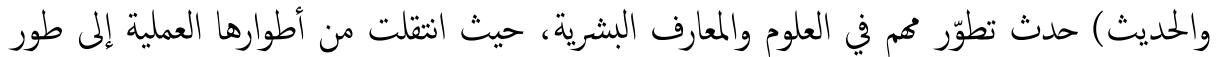

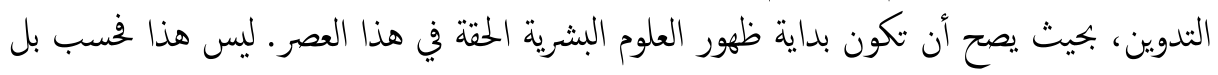

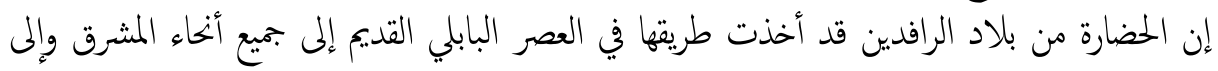
أطراف العالم القصية. آخر العهود الزاهرة في العصور القديمة كان بين (626-539ق.م.). ويعد حكم (نبوخذ نصر الثناني)

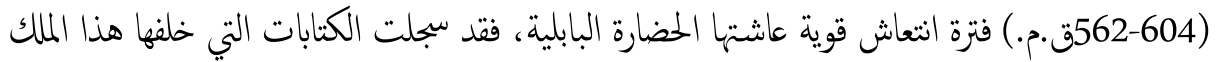

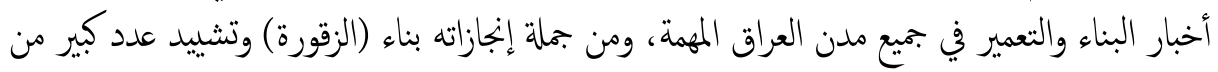

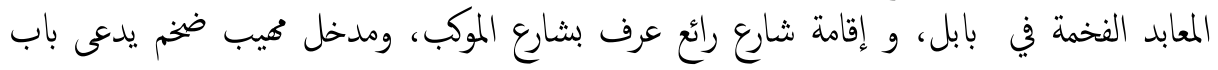


عشتار، يقع وراء هذا الباب قصره الفخم بجنائنه المعلّقة، الذي عرف في المصادر اليونانية بإحدى تاني

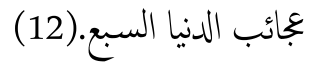
اله ان تلك الانجازات الحضارية الخختلفة تعرضت في فترات تاريخية عديدة، الى التدمير تارة او الى تاثير

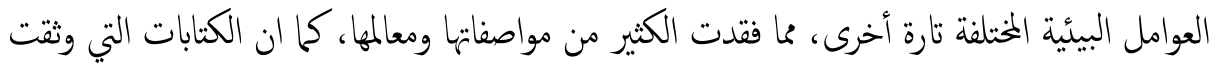

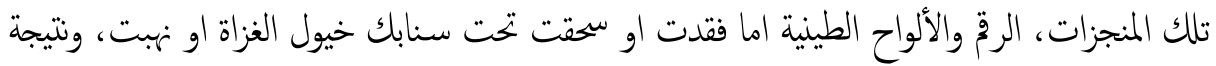

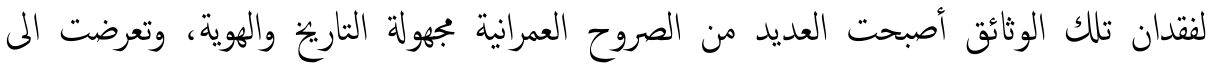

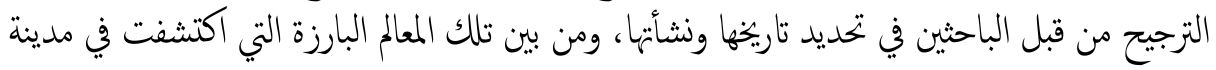

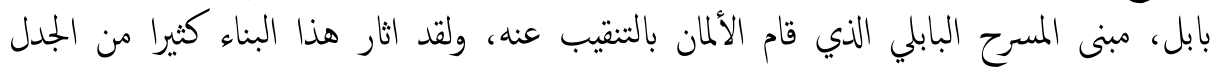
والتساؤل:

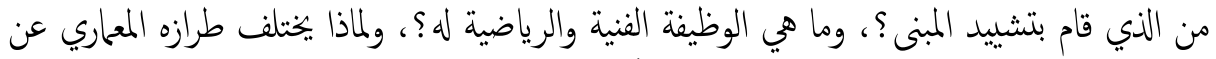

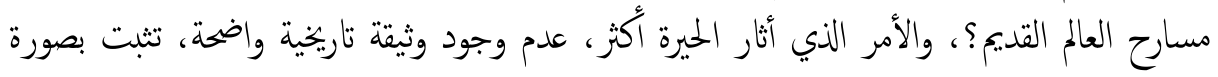

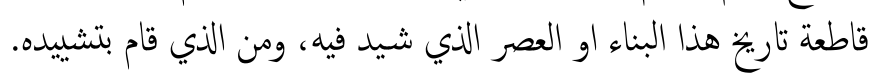

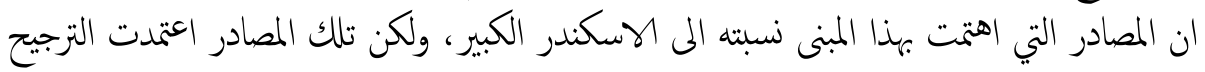

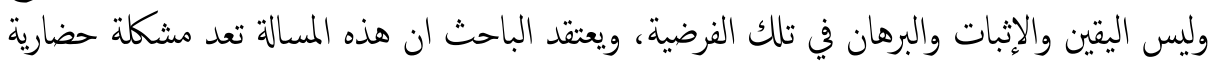

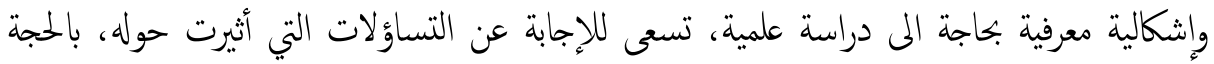

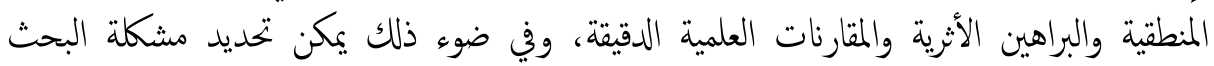

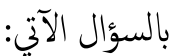

متى بني المسرح في مدينة بابل، ومن الذي قام بتشييده، وما هي الخصوصية الممحارية والوظيفية لهذا

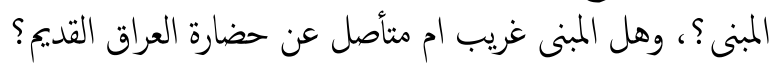

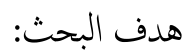

ههدف البحث الى الكشف عن فترة تشييد مبنى المسرح البابلي وتعرف خصائصه ووظيقته الثقافية.

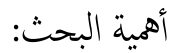

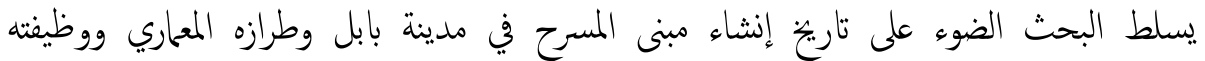

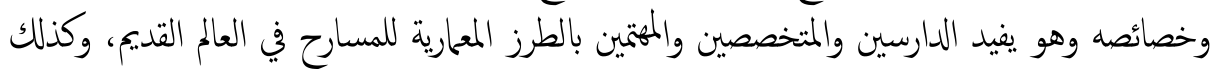

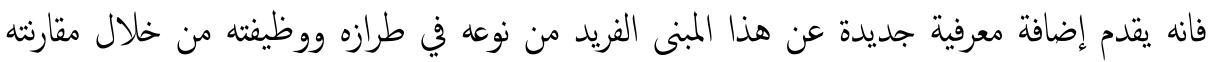

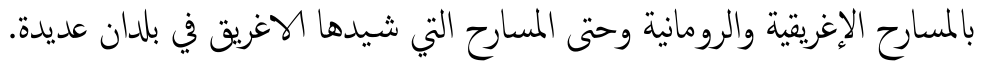

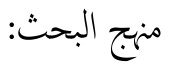
اعتمد الباحث المنهج التاريخي في التحقق من الوثائق والشواهد الأثرية، وكذلك المنهج المقارن 
من خلال إجراء مقارنة بين المسرح البابلي والمسرح الإغريقي والروماني. الإطار النظري - (المبري

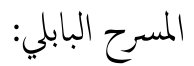

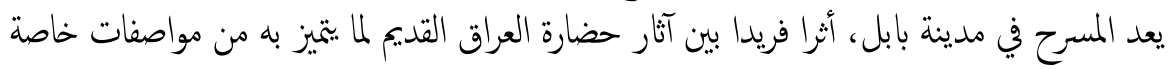

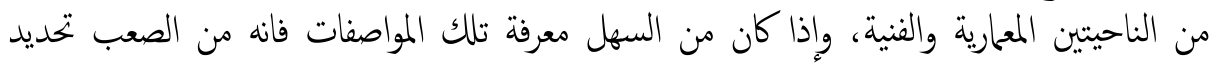

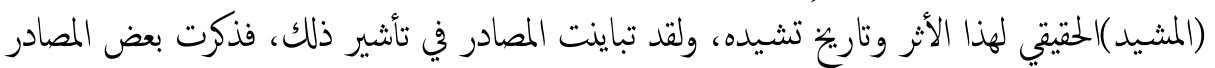

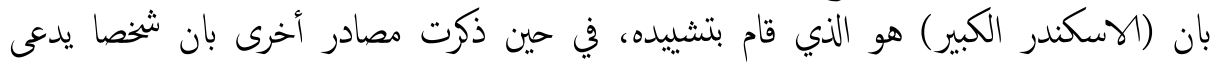

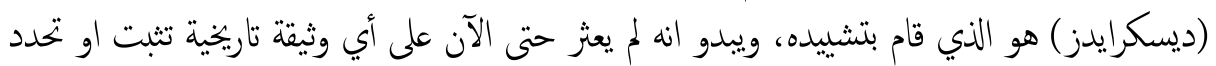

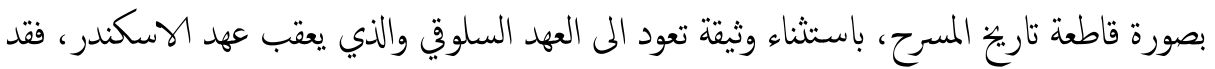

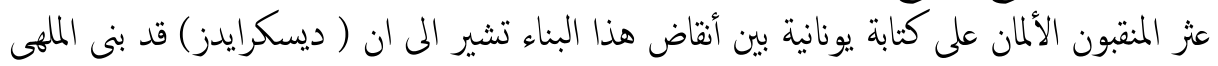

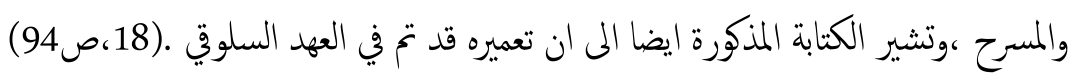

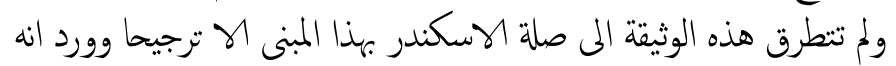

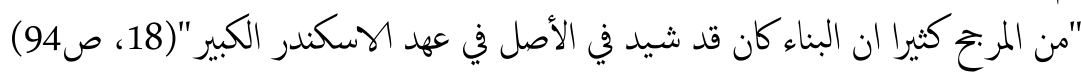

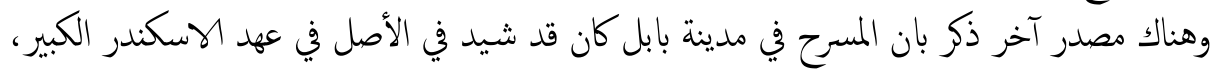

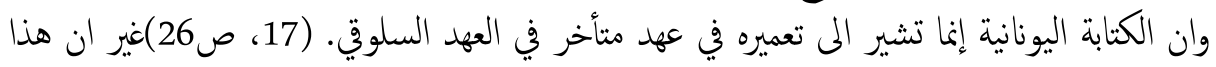

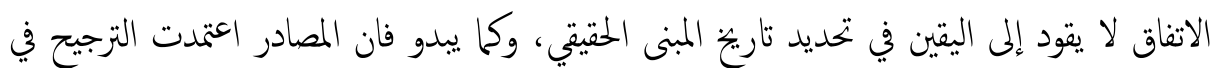

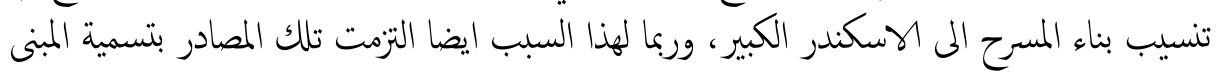
- المسرح الإغريقي- وفقا الى الكتابة اليونانية.

\section{مخطط المسرح البابلي:}

يتألف مبنى المسرح البابلي من ثلاثة أجزاء رئيسة هي:

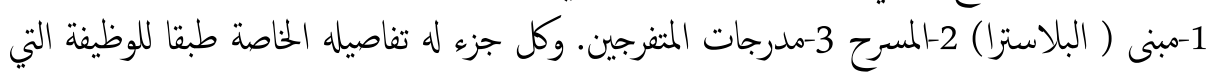

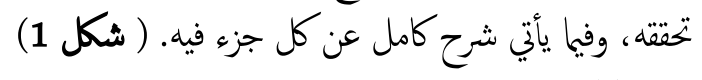
مبنى البلاسترا:

البلاسترا هو ملعب عبارة عن ساحة مربعة الشكل تحف بها سلسلة من الومعدة، وعلى أطرافها

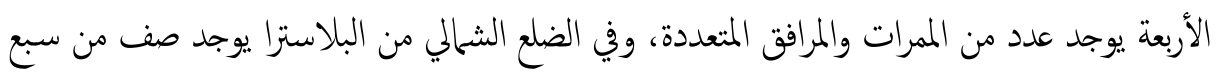

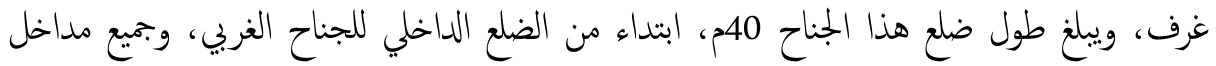

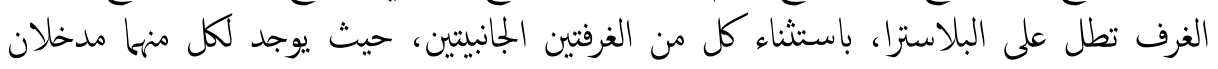

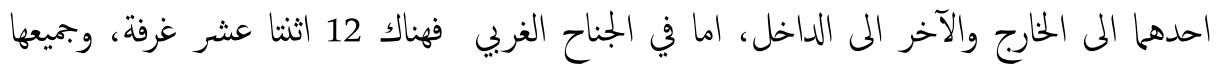


متساوية في المساحة تقريبا، ويبلغ طول هذا الجناح 70م، والغرفة الثمالية من الضلع الغربي متقدمة عن الفنا

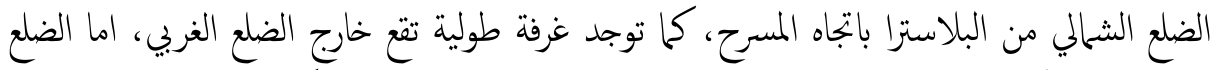

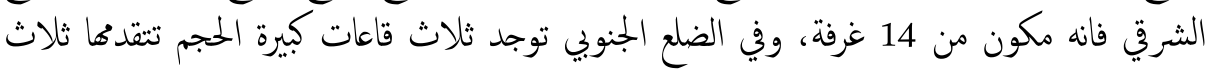

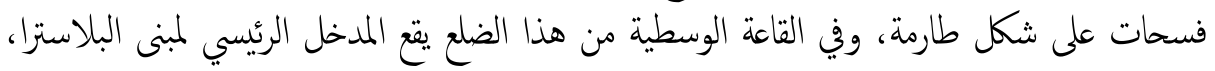

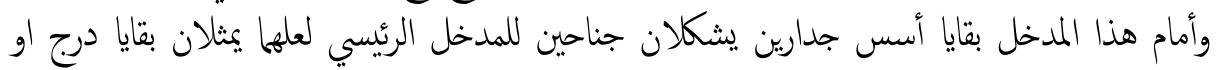

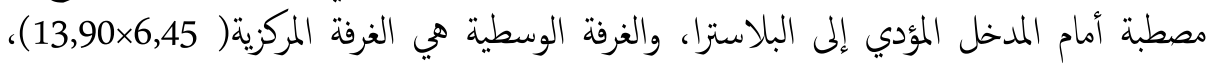

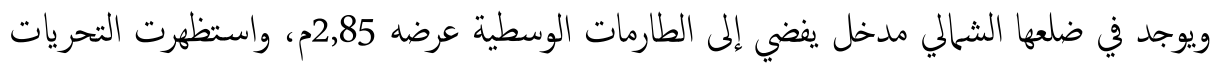

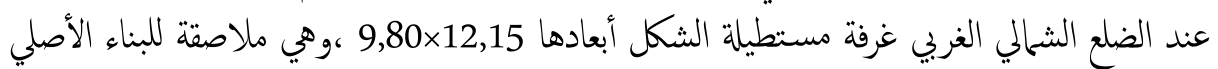

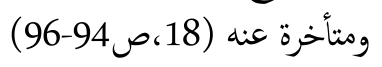

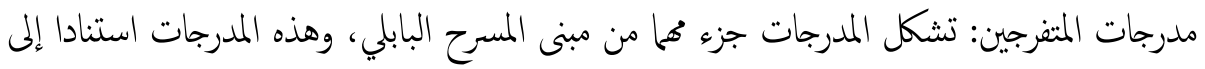

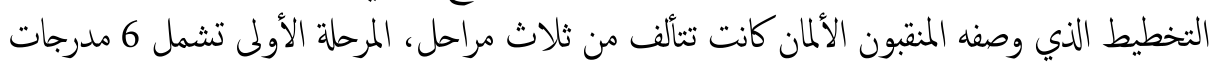

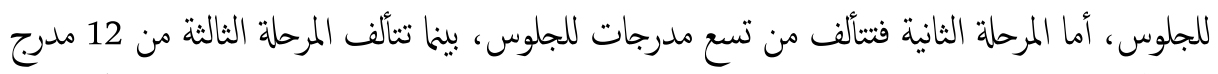

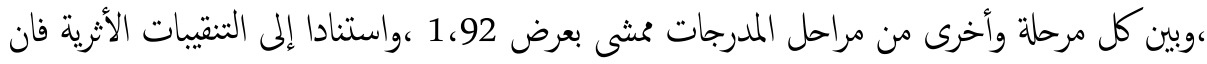

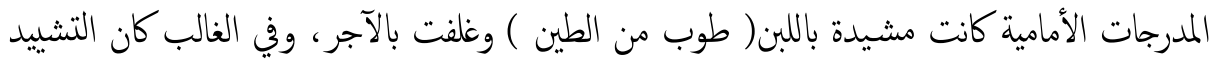

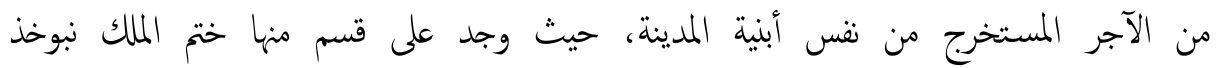

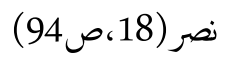

وهناك جدار سميك من اللبن يسند هذه المدرجات من الخلف. بناية خشبة المسرح: هذه البناية

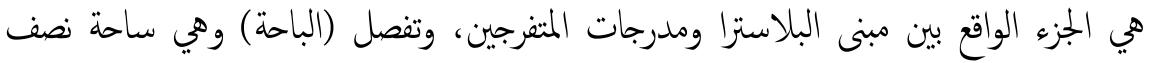

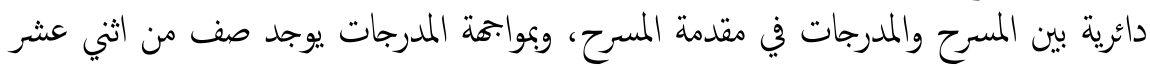
عمودا، كل عمود مستطيل الشكل ووابجته نصف دائرية ومبنية بالآجر ، ويعتقد المنقبون الألمان

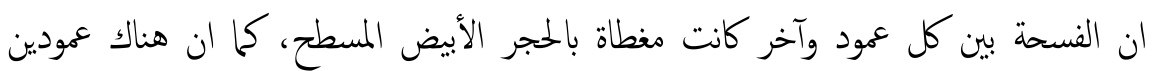

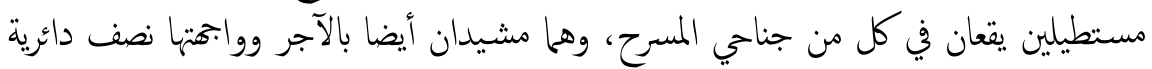

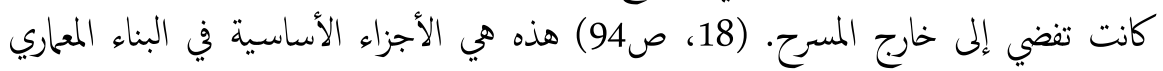

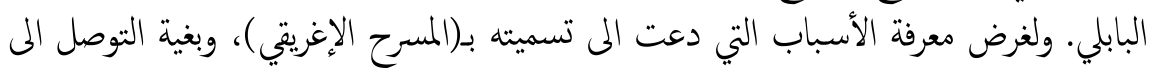

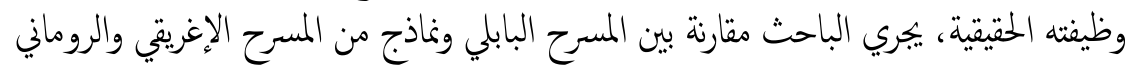

$$
\text { الطراز المعحاري للمسرح الإغريتي: }
$$

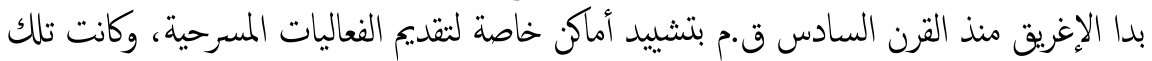

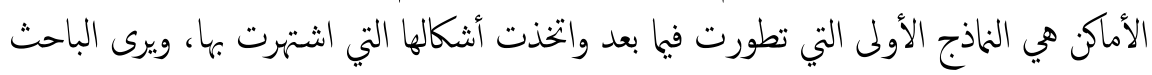


ضرورة دراسة أمه الناذج للتوصل المى عناصر التشابه والاختلاف بين المسرح البابلي والمسارح

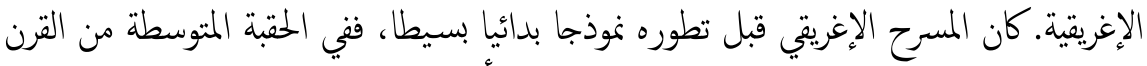

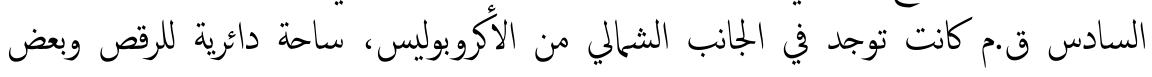

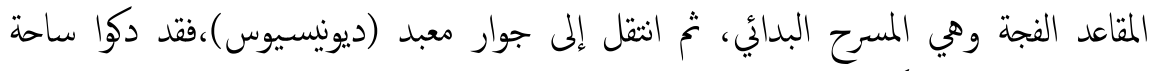

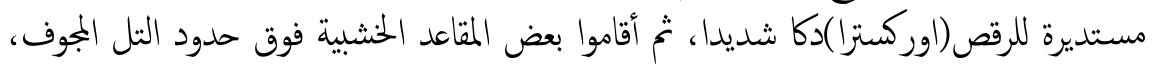

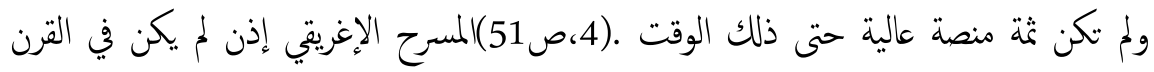

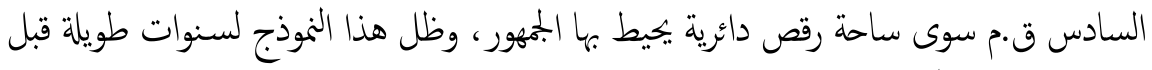

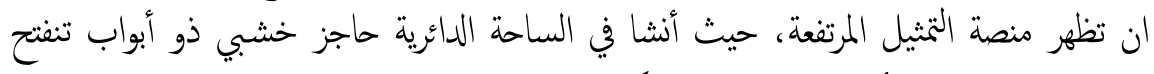

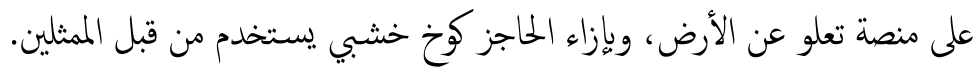

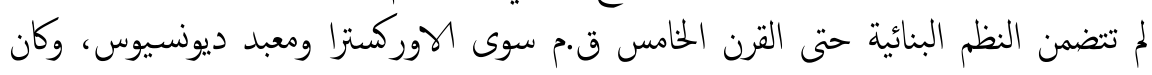

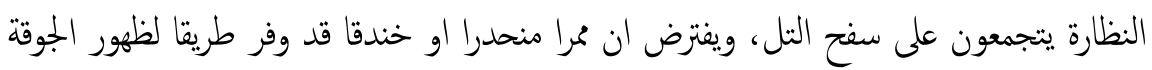

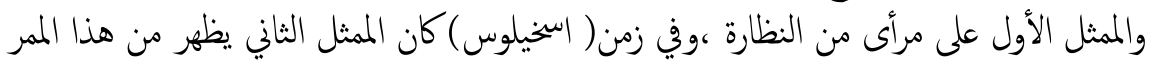

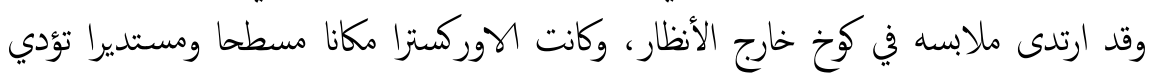

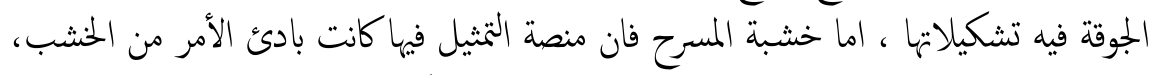

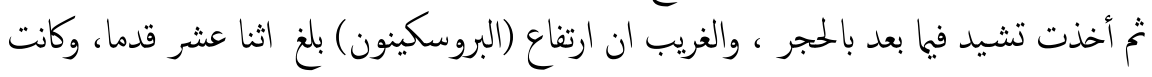

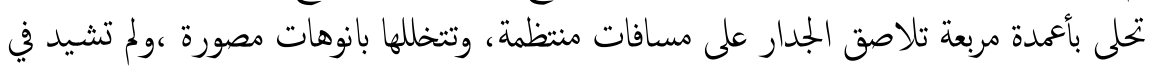

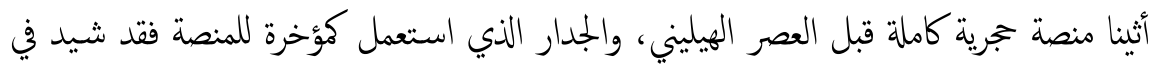

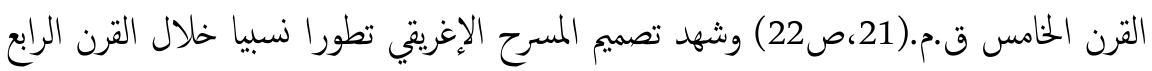

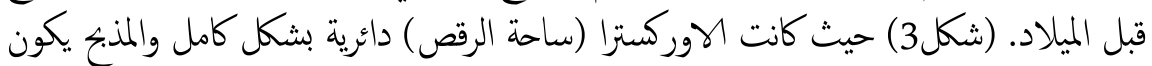

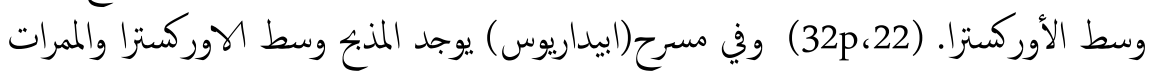

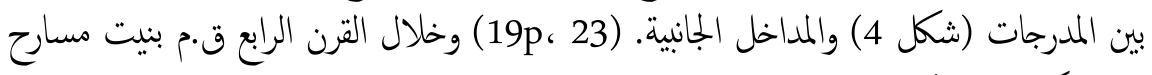

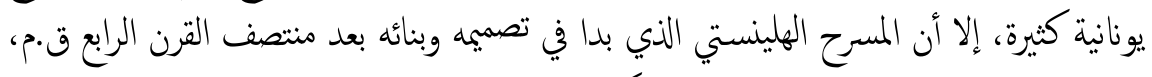

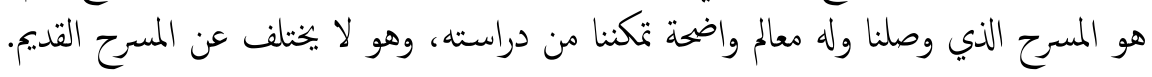

ويتكون هذا المسرح من الأجزاء الآتية:

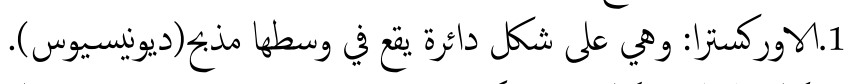

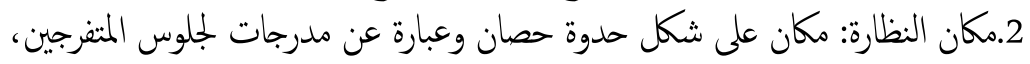
ويوجد مران جانيان لدخول الجوقة الى الاوركسترا وكذلك لدخون الدول المتفرجين. 


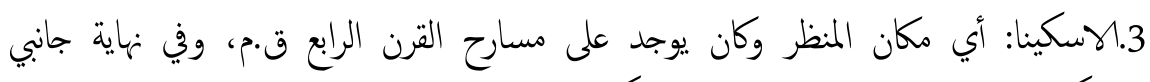
الاسكينا عمودان بارزان يعرفان باسم (بارسكينا).

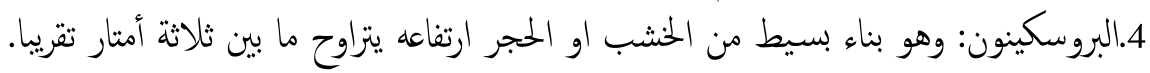

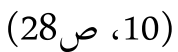

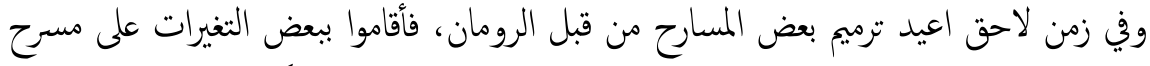

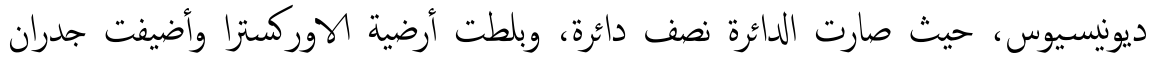
حول الوركسترا.

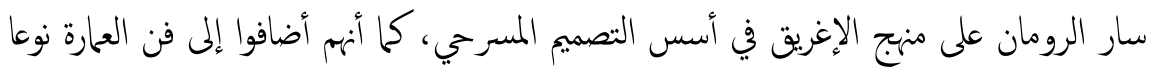

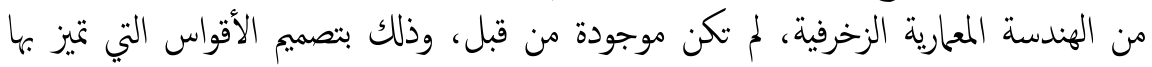

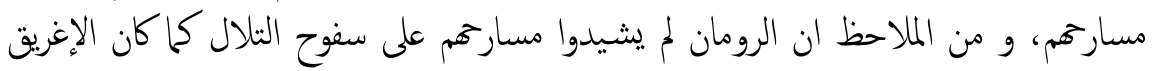

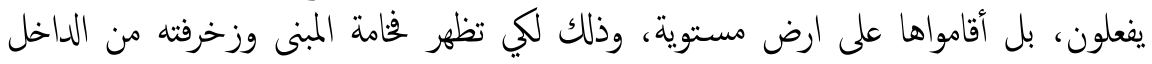

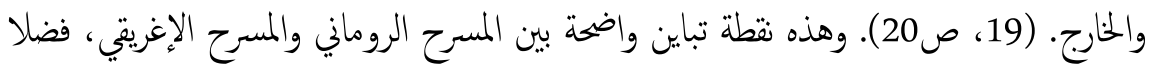

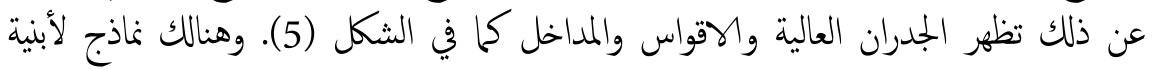

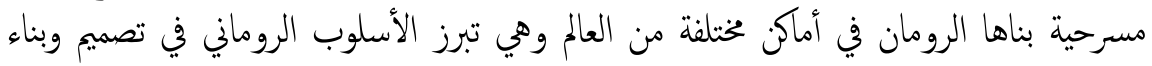

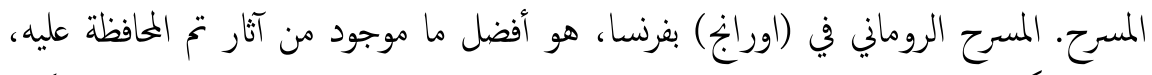

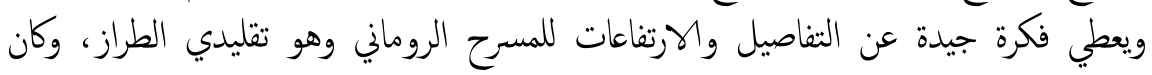

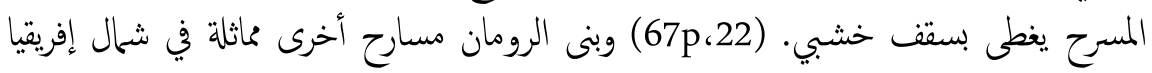

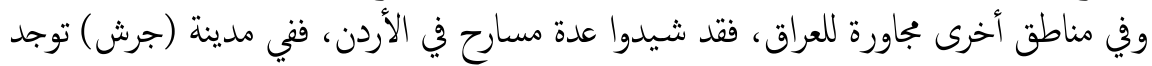

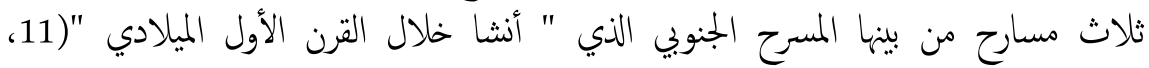

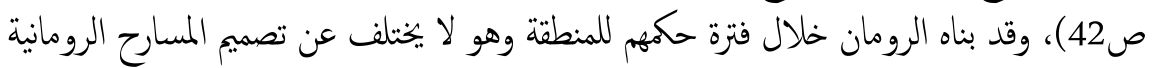
الأخرى الا بتفاصيل بسيطة وفي أبعاد أجزائه.

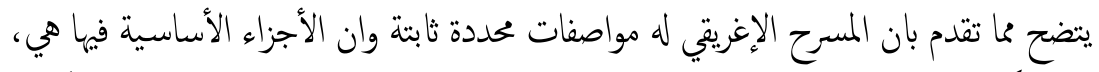

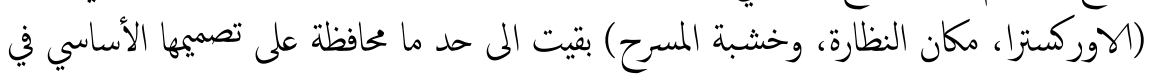

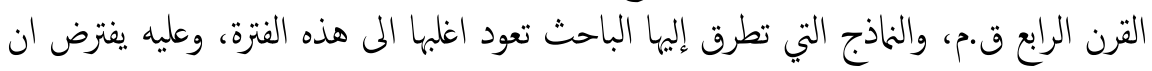

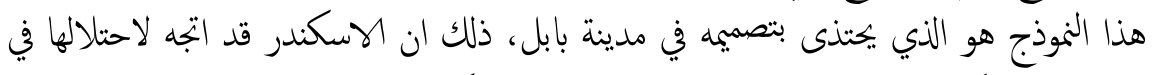

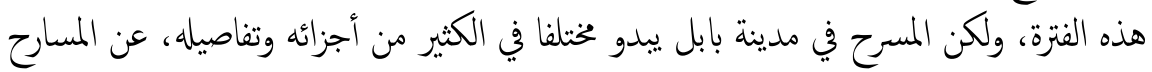

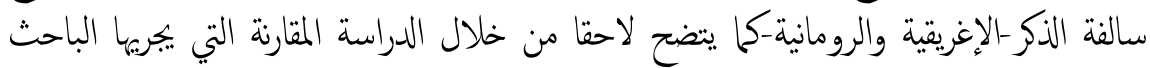




\section{إجراءات البحث:}

\section{الدراسة التحليلية المقارنة}

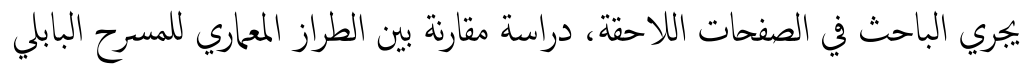

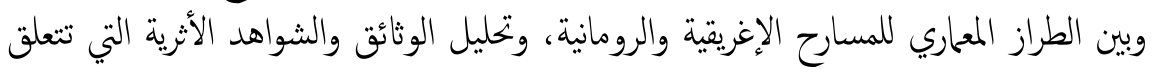
بناريخ إنشاء هذا المسرح.

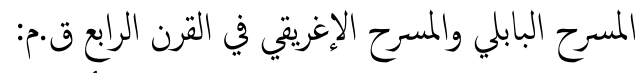

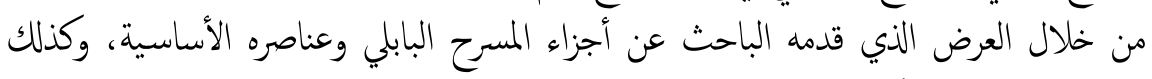

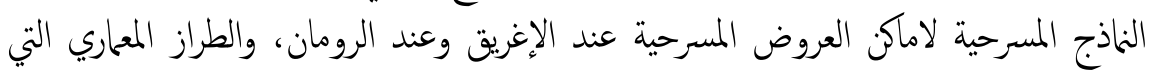

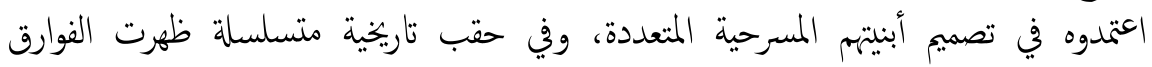
والاختلافات الآتية:

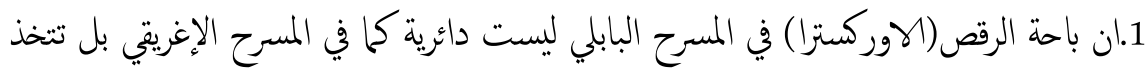

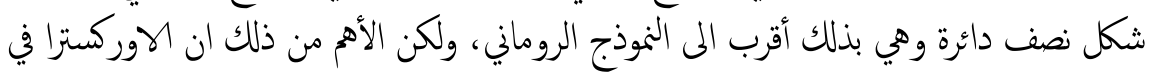

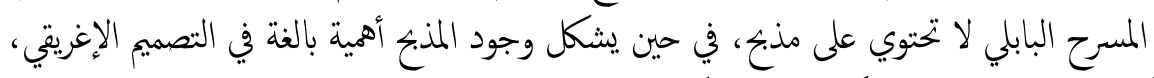

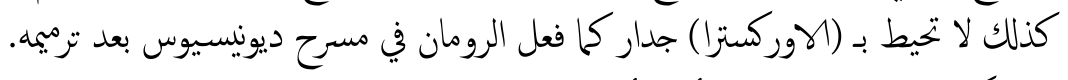

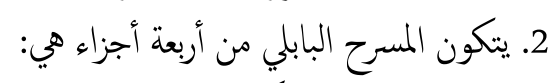
مكان النظارة، الاوركسترا، خشبة المسرح، ومبنى البلاسترا.

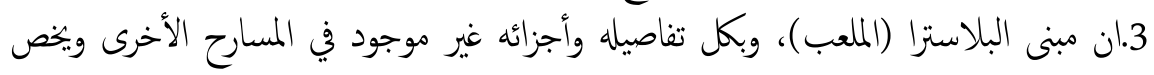
فقط الطراز المعاري للمسرح البابلي الذي ينفرد بهذه الإضافة.

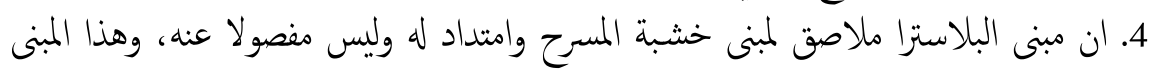

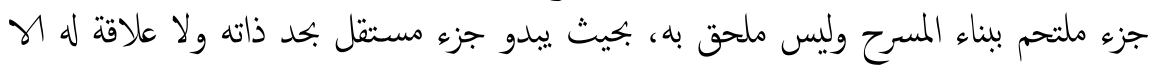
بالمجاورة فسب.

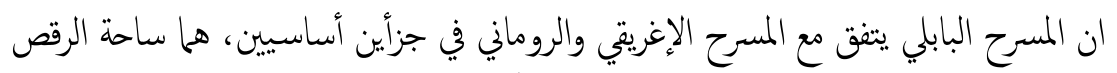

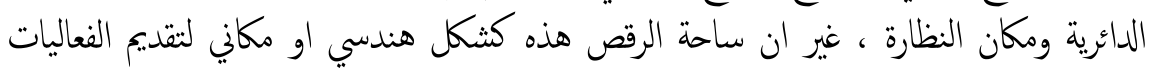

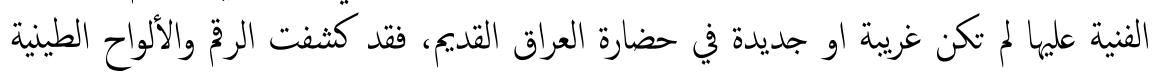

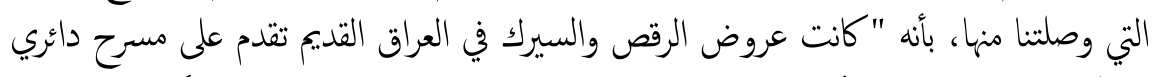

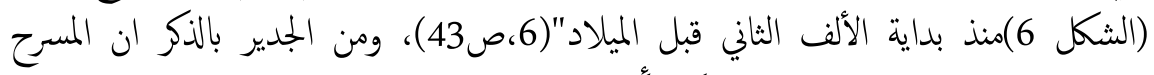

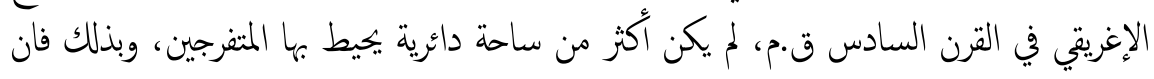




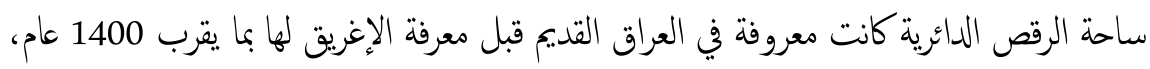
ولم تكن مجرد ساحة بل مكان لتقديم الفعاليات الفنية فيها.

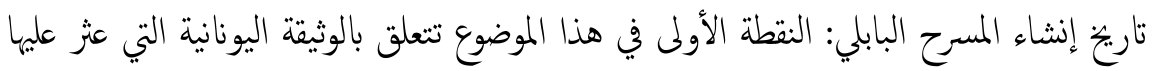

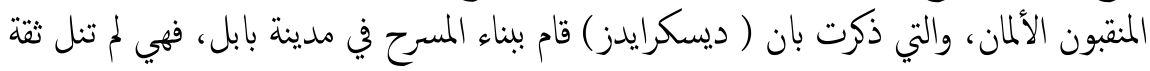

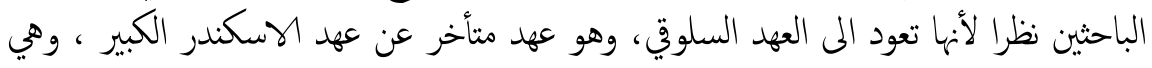

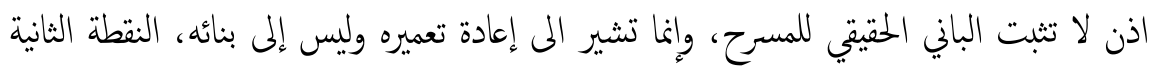

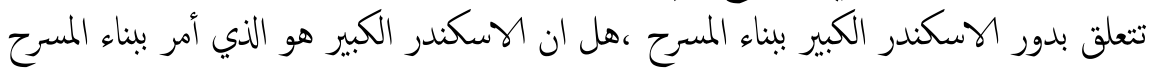

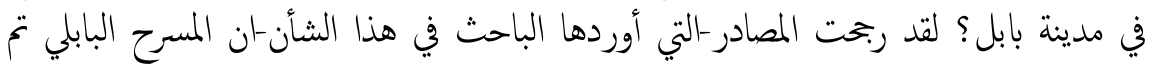

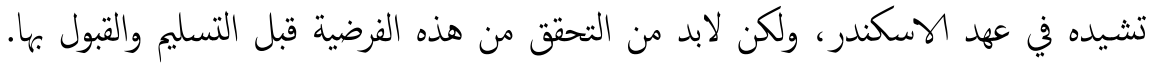

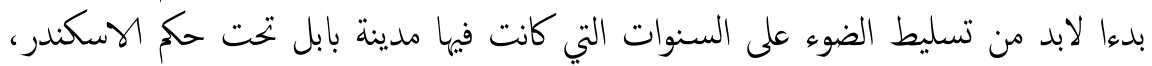

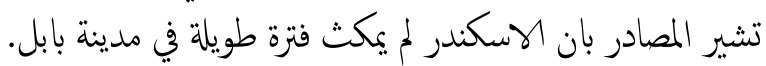

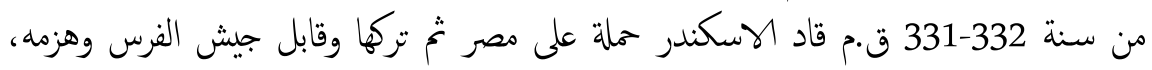

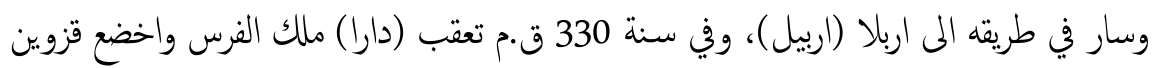

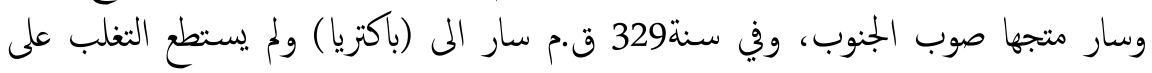

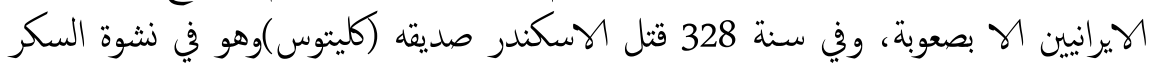

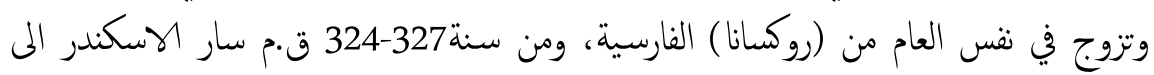

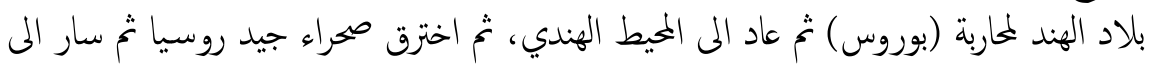

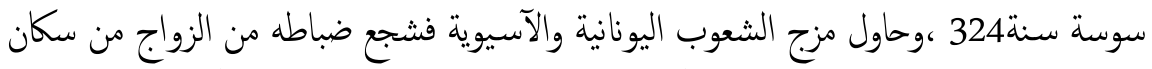

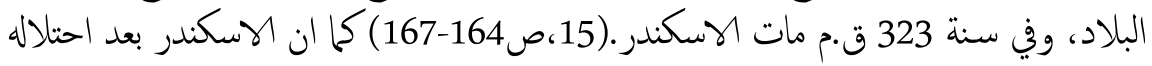

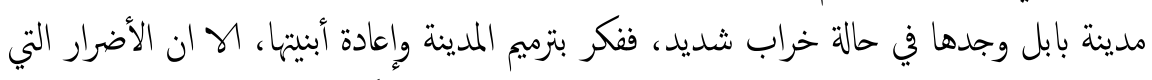

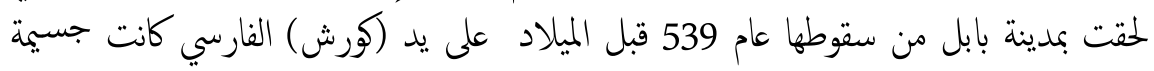

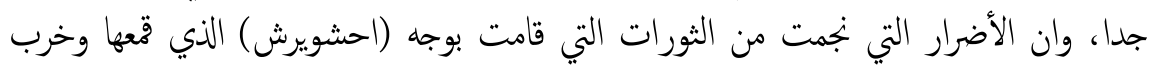

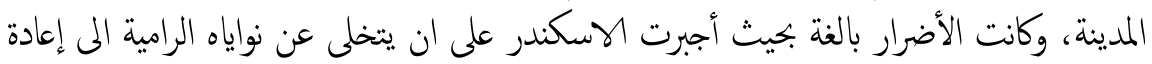

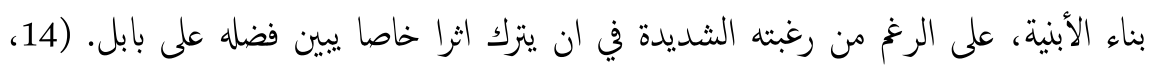

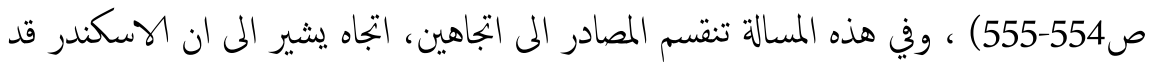

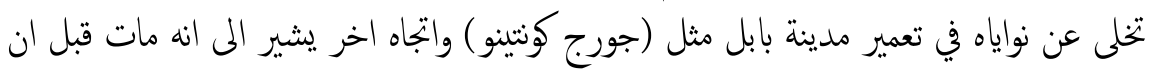

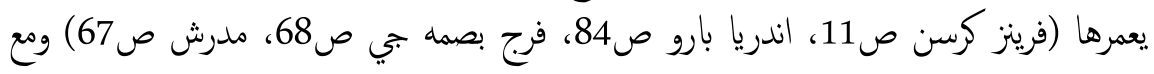


ذلك فان النتيجة واحدة، وهي ان مدينة بابل لم تعمر خلال عهد الاسكندر فكيف اذن بيني

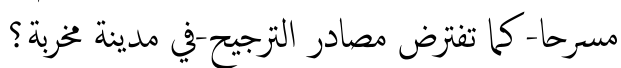

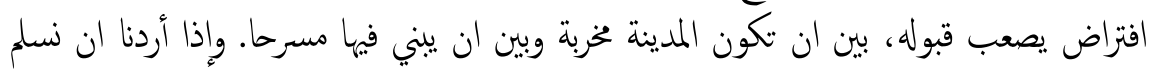

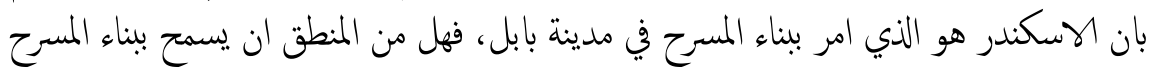

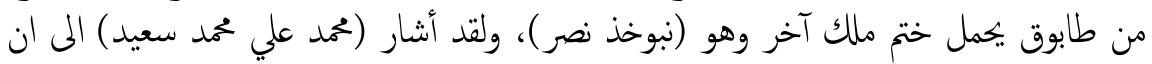

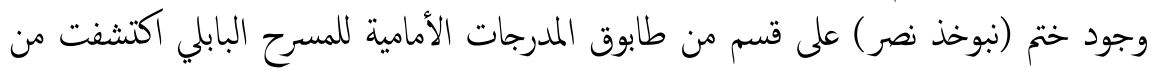

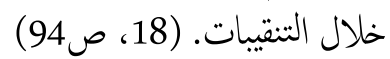

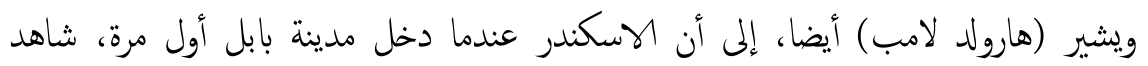

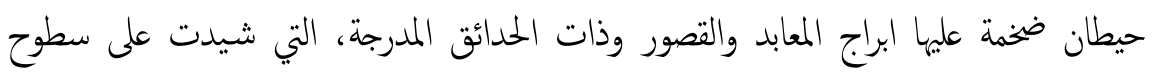

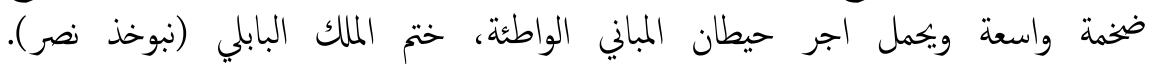
(221 (20)

ويتضمن ختم الملك (نبوخذ نصر) على الطابوق، العبارة الآتية، " نبوخذ نصر ملك بابك بابل، حابي

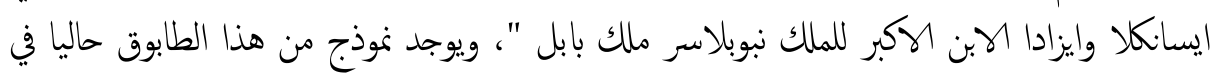

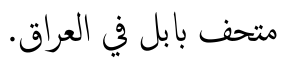

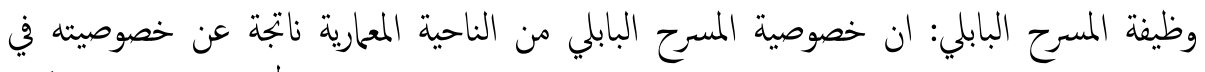

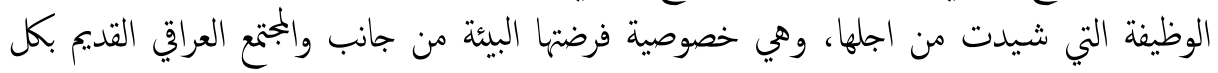

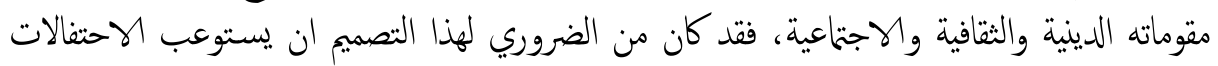

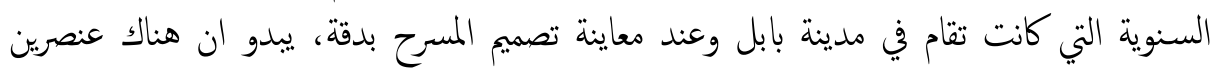

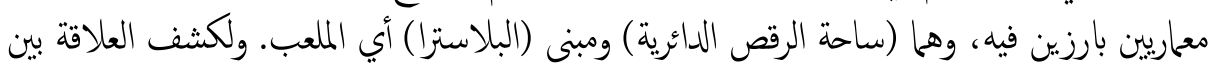

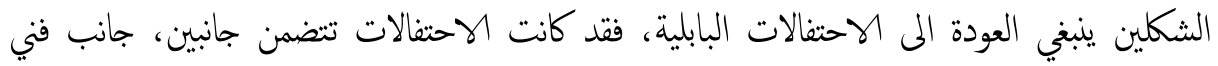

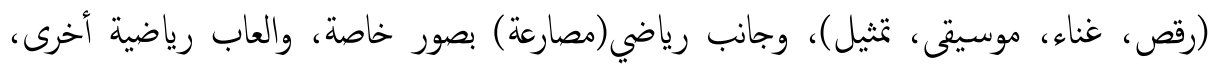

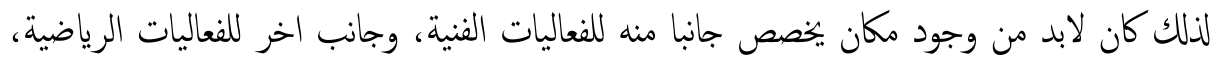

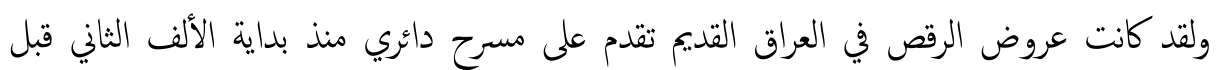

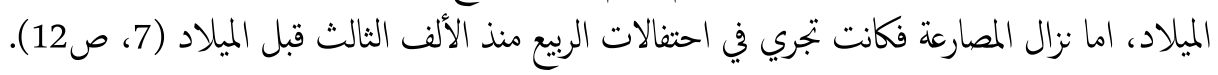

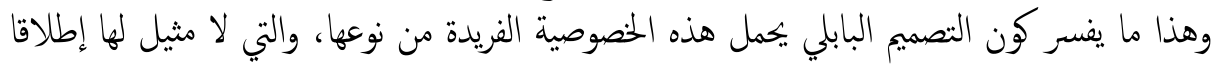

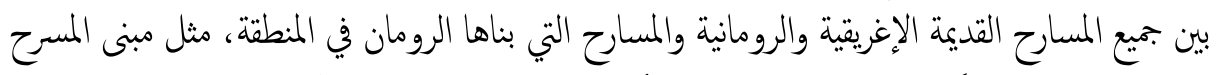

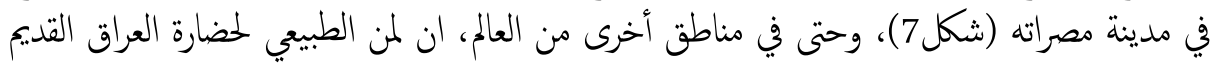

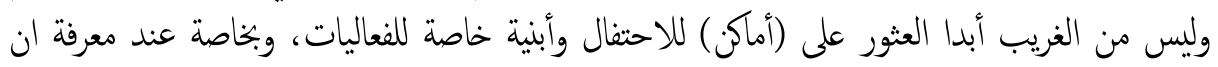


أنشطة مسرحية ذات أهمية بالغة كانت تقدم أثناء تلك الكتاكتفالات الشعبية والرسمية خلال السنة وتتضمن تلك الفعاليات والأنشطة التمثيلية ما يأتي:

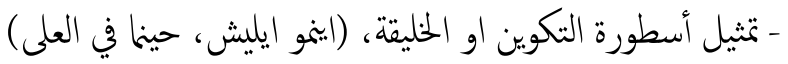

$$
\begin{aligned}
& \text { - تمثيل أجزاء من ملحمة (جلجامش). } \\
& \text { تمثيل نص رثاء اورن } \\
& \text { تمثتيل موت وقيامة الإله (مردوخ). }
\end{aligned}
$$

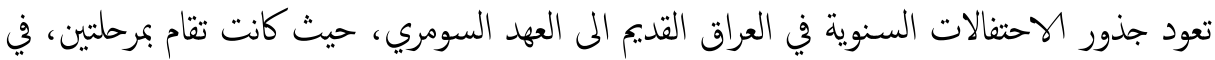

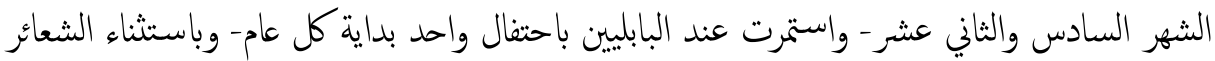

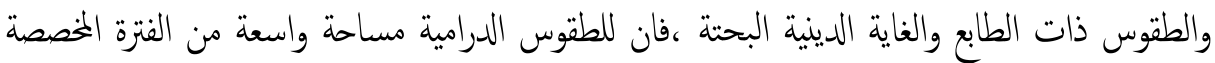

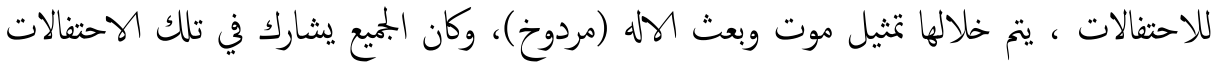

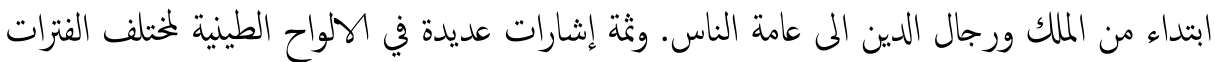

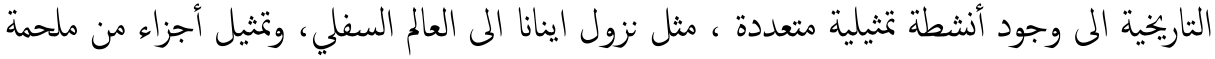

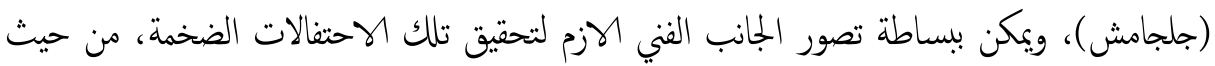

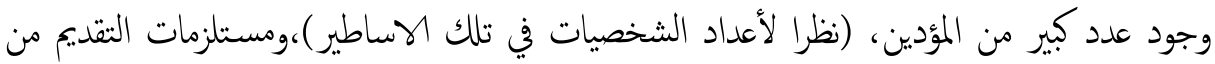

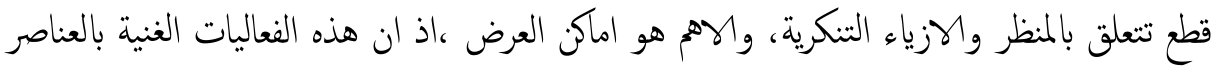

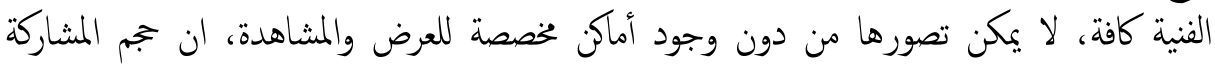

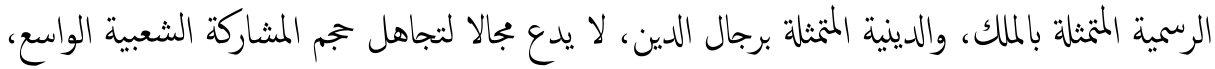

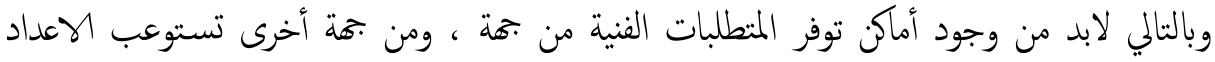

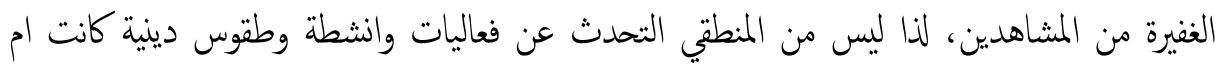

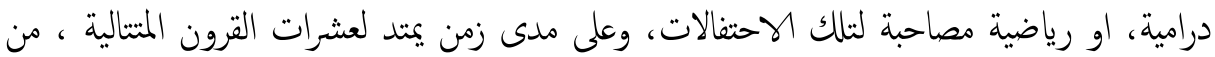

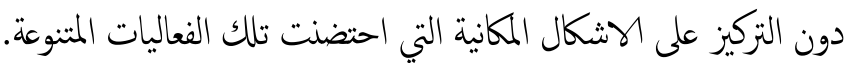

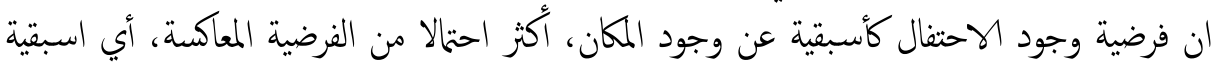

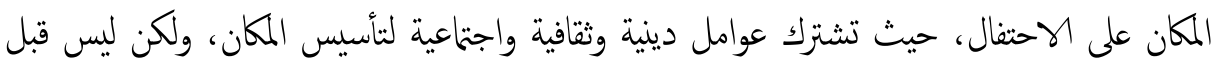

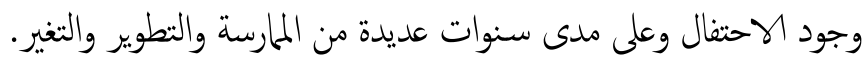

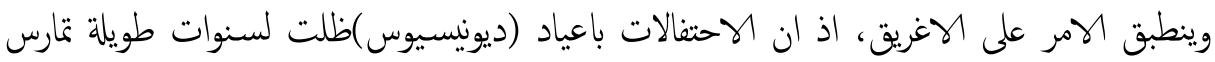

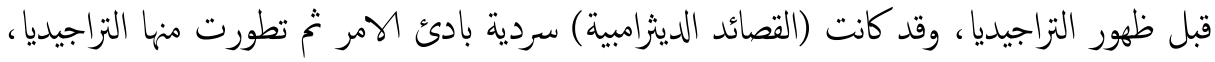

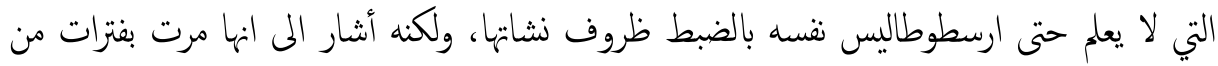
التغير حتى استقرت على الشكل الذي بدا عليه في القرن الخامس قبل الميلاد.

\section{6}


يرى الباحث بان انثاء المباني ماكانت تتم من دون وجود حاجة فعلية لتنظيم انشطة او فعاليات معينة

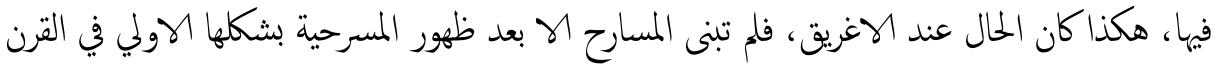

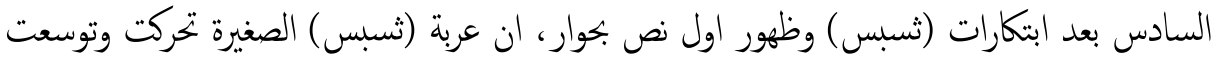

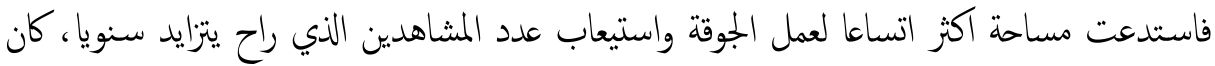

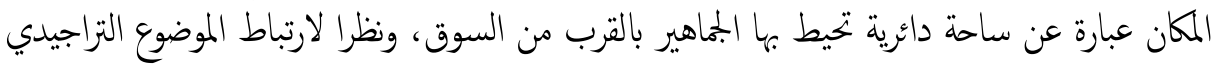

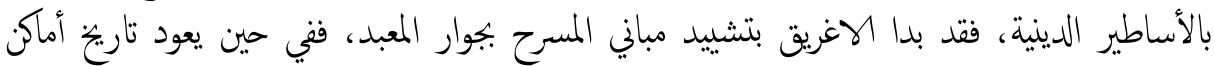

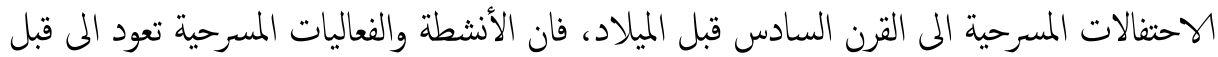

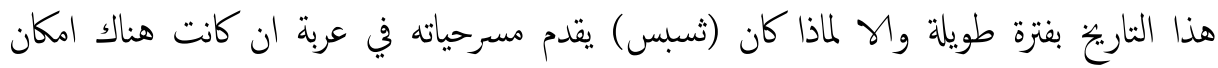
لمرض

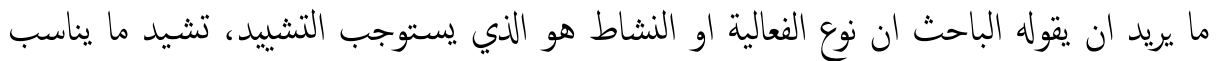

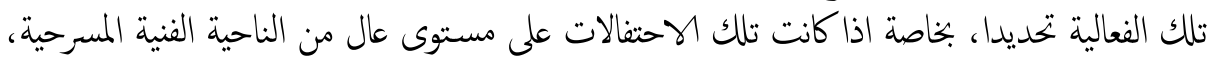

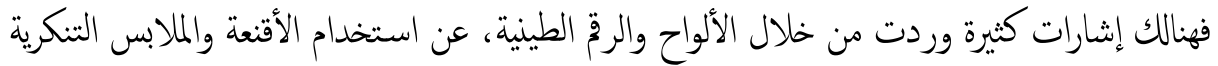

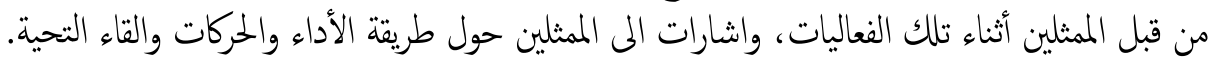

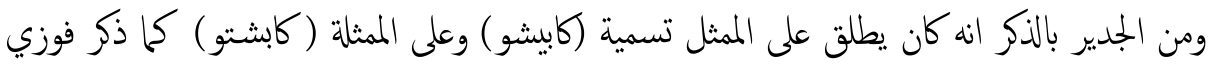

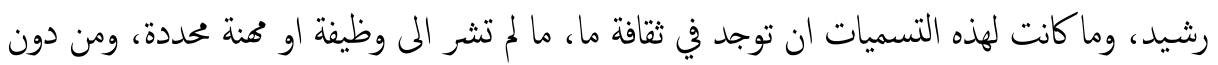

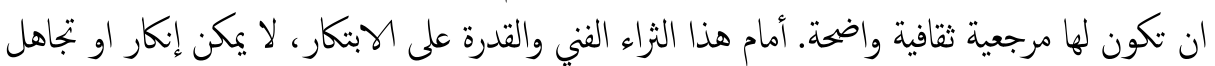

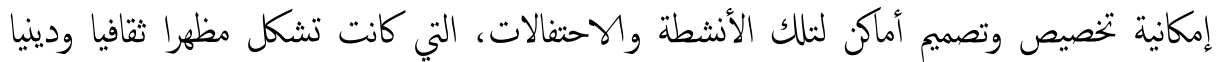
واجتاعيا بالغ الأهمية، وليس غريبا ان يكون مبنى المسرح البابلي أحد تلك الأماكن.

\section{الاستنتاجات:}

أولا: ان طراز المسرح البابلي من حيث النكوين الهندسي والمعهاري ينفرد بخصوصية لا تشابه طرازيه

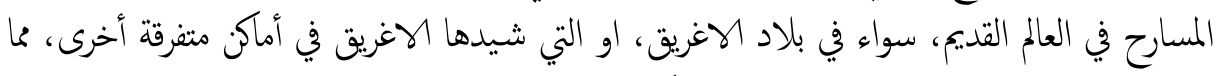

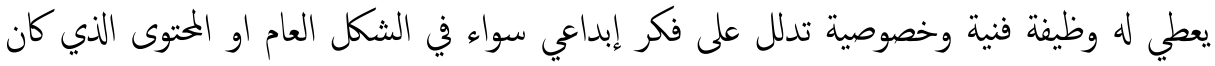
يقدم عليه.

ثانيا: ان تفرد المسرح البابلي المعحاري والوظيفي يؤكد أصالة وانتماء هذا المبنى المى البنية الثقافية

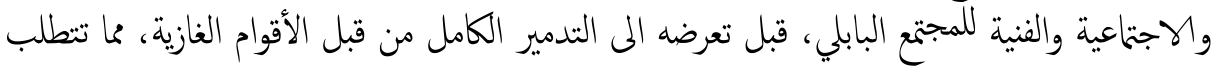

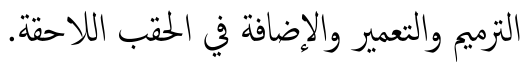

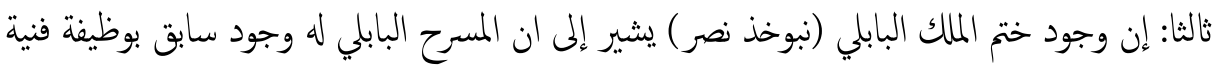

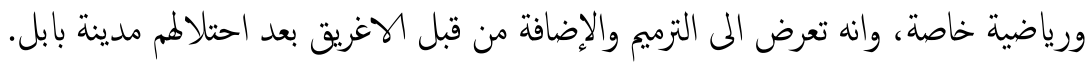


محمد صبري صاخ المسرح البابلي، تأريخه وطرازه وخصائصه... - المان.

رابعا: إن ساحة الرقص الدائرية (الاوركترا) هي فكرة عراقية أصيلة، باعتبارها شكلا هندسيا أوليا

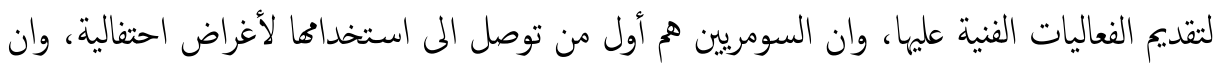

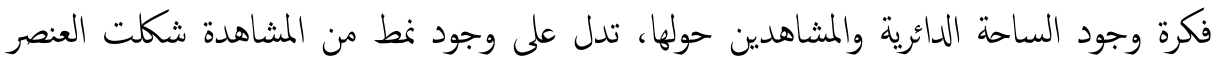
الأساسي في البناء المعحاري المسرحي.

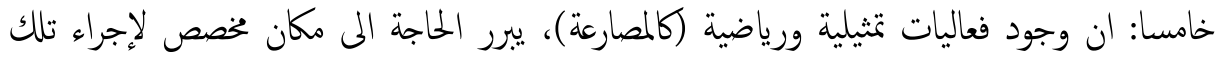

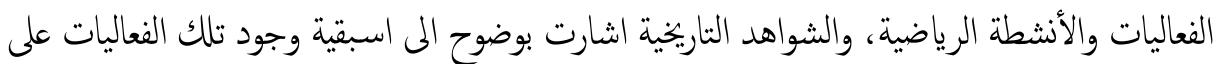

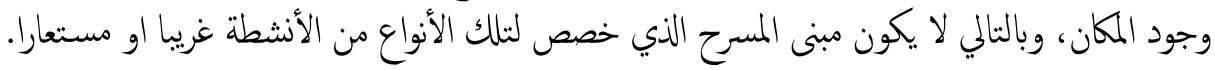

\section{جدول الششكال:}

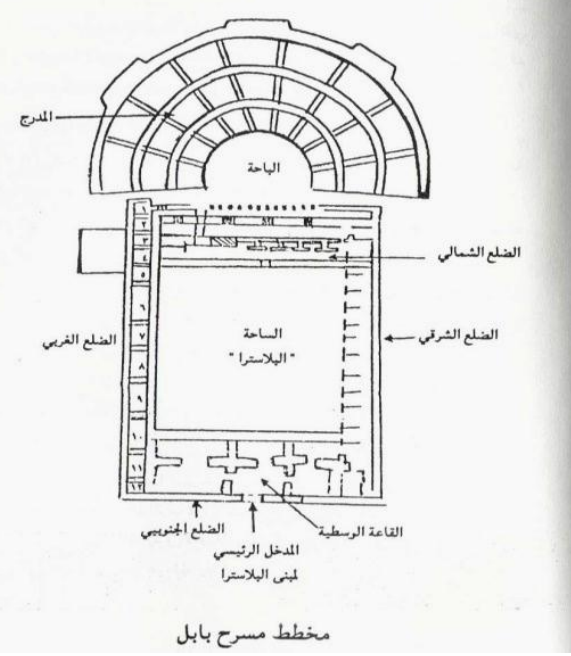




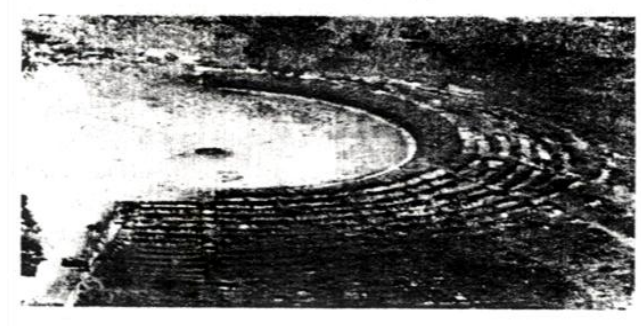

(شكل 2 المسرح الإغريقي في القرن السادس ق.م)

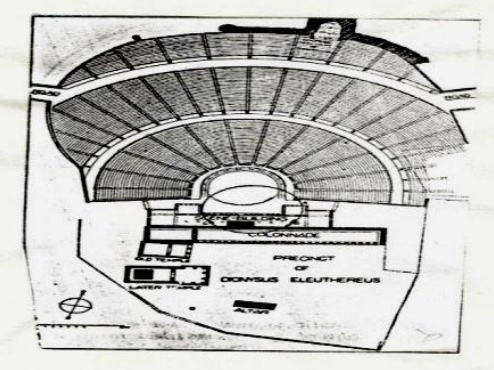

$$
\text { (شكل } 3 \text { المسرح الاغريقي القرن الرابع ق.م) }
$$

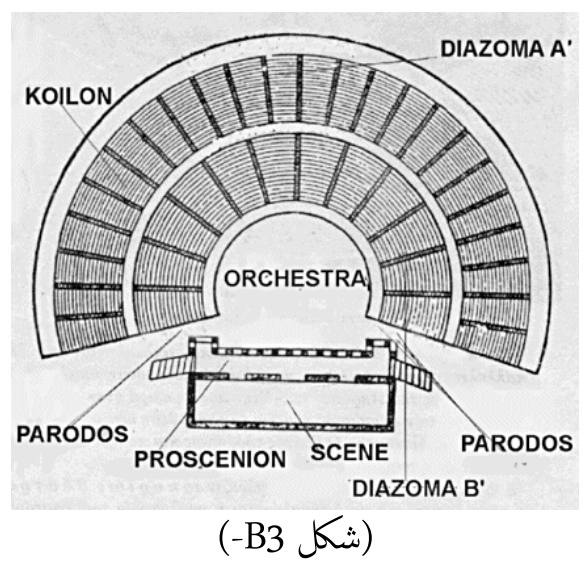




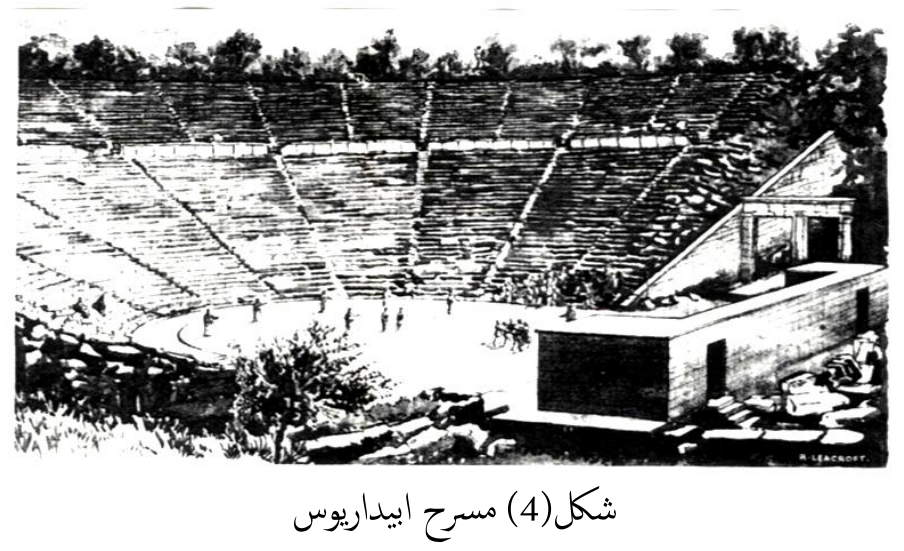

The parts of a Roman theatre and the use of amphitheatres: 31
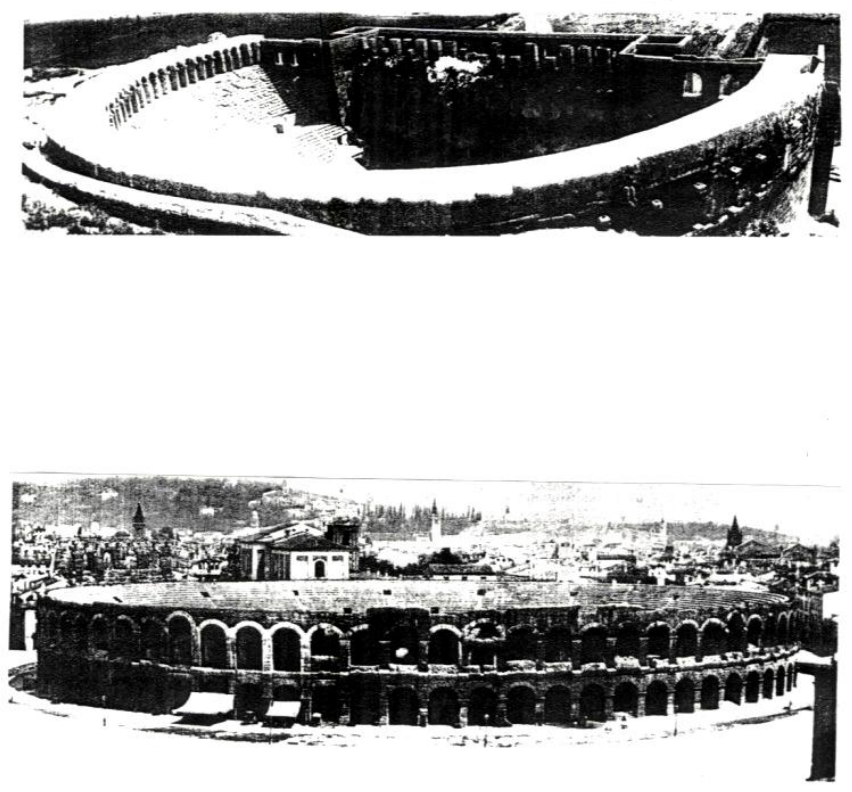

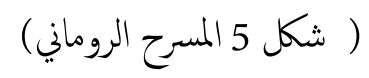


(ممد صبري صاخ

المسرح البابلي، تأريخه وطرازه وخصائصه...

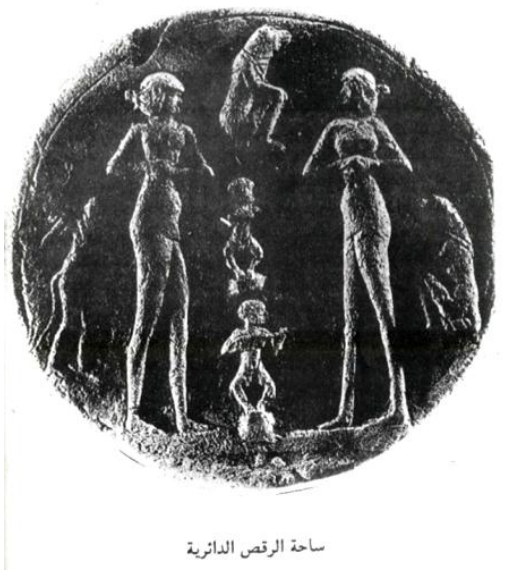

شكل 6

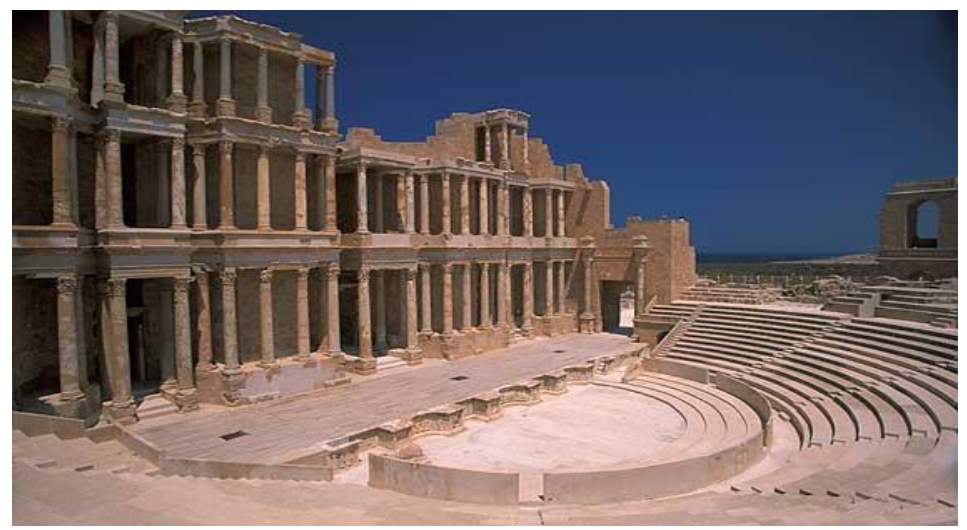

شكل 7-المسرح في مدينة صبراتة

凷111 81 


\section{قائمة المصادر:}

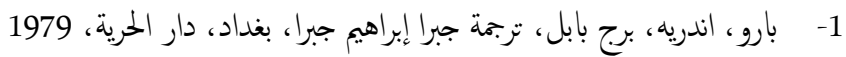

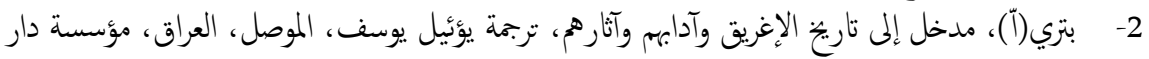

$$
\text { الكنب، 1977. }
$$

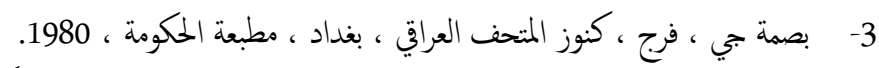
4- تشيني، شلدون، تاريخ المسرح في 3000عام، ترجمة دريني خشبه، القاهرة، مكتبة الآداب،

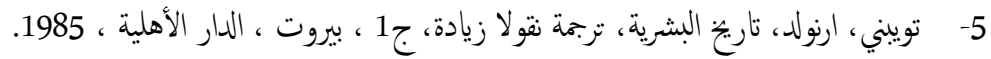

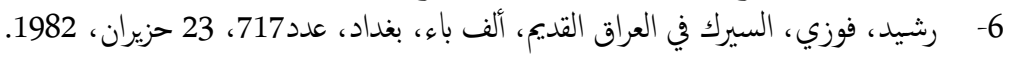

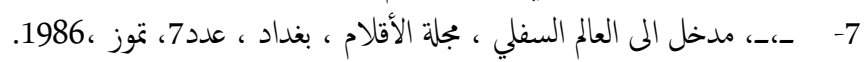

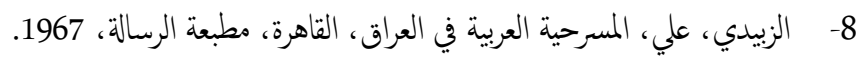

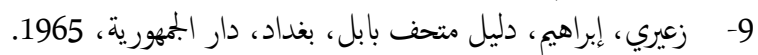

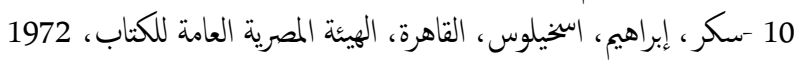

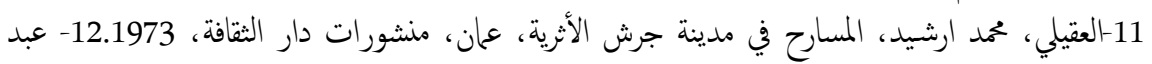

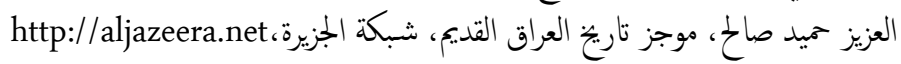

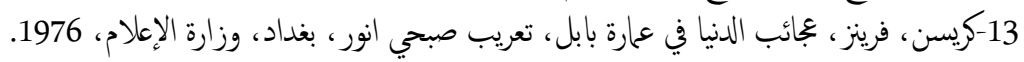

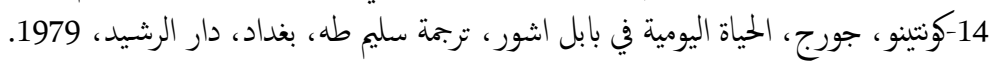

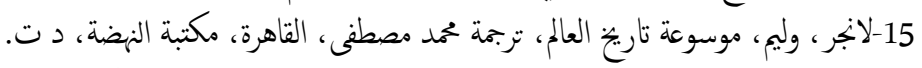

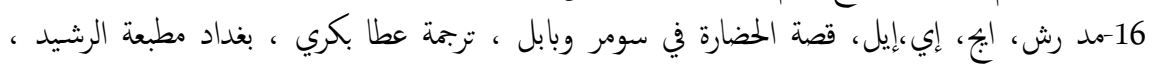

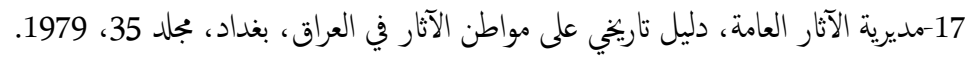

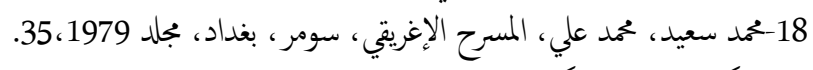

19-مليكه، لويس، الديكور المسرحي، القاهرة، الدار القومية، 18 الميل، 1966.

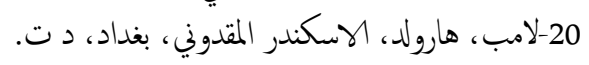

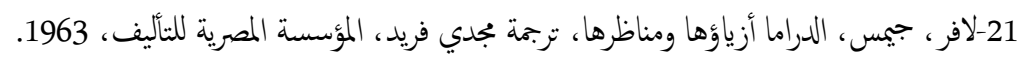

22- Robert, Vera mowry, On Stage ahistory of theatra , second edition,

Newyork, Harper s Row ,publishers ,1974.

23- Richard, Theater and playhouse, newyork, by paber back 1985 .

\section{(65에에 82}

